\title{
Evidence on the effects of exercise therapy in the treatment of chronic disease
}

\author{
U M Kujala
}

Department of Health Sciences, University of Jyväskylä, Jyväskylä, Finland

Correspondence to: U Kujala, Department of Health Sciences, University of Jyväskylä, PO Box 35 (LL), FIN40014,Finland; urho.kujala@ sport.jyu.fi

Accepted 23 April 2009 Published Online First 29 April 2009

\section{ABSTRACT}

Evidence on the effects of exercise in the treatment of patients with chronic diseases should be based on well designed randomised controlled trials. The most consistent finding of the meta-analyses summarised in the present work is that aerobic/functional capacity and muscle strength can be improved by exercise training among patients with different diseases without having detrimental effects on disease progression. This is important, as with population aging exercise therapy may be an important means of reducing disability and increasing the number of older people living independently. Additionally, there is accumulating evidence that in patients with chronic disease exercise therapy is effective in improving the prognostic risk factor profile and, in certain diseases, in delaying mortality. In some diseases, such as osteoarthritis, pain symptoms may also be reduced. Severe complications during the exercise therapy programs were rare.

Conclusive evidence as to the benefits of exercise in the treatment of patients with chronic diseases within the limited resources of the healthcare system should be based on well designed randomised controlled trials (RCTs). These in turn should be based on a plausible account of how (via what mechanisms) exercise benefits the patient.

As patients with chronic diseases may be at risk for exercise-related cardiovascular or other complications, doctors often need to issue such patients with guidelines for a safe training program.

Exercise therapy for chronic diseases can be either generalised aerobic or strength training or condition-specific training. A typical example of generalised training is aerobic or strength training causing systemic effects, such as that on insulin sensitivity in the treatment of type 2 diabetes mellitus. Condition-specific training may include, for example, a series of specific movements with the aim of promoting good physical health, such as strengthening the low back muscles in patients with low back pain or pelvic floor muscle training in patients with urinary incontinence.

Recently, the number of RCTs evaluating the effects of physical exercise therapy in the treatment of specific diseases and related functional impairments has increased substantially allowing systematic reviews including meta-analyses. This review summarises the evidence so far on the effects of exercise therapy in the treatment/ rehabilitation of different chronic diseases.

\section{METHODS}

\section{Search strategy and selection criteria}

This paper is a summary of the evidence to date from systematic reviews of at least three randomised controlled trials investigating the effect of exercise therapy on the same outcome among patients with the same chronic disease. For studies to be included in this summary review, the intervention and the control groups had primarily to be contrasted by exercise (most commonly exercise training + usual care vs usual care). This review is based on previous repeated searches of the literature ${ }^{1}$ and contacts with the authors of different systematic reviews. For this update review, final literature searches of computer databases (PubMed, Cochrane Database of Systematic Reviews) were performed for the period from January 2001 up to and including December 2008.

Reviews that were not updated after the year 2000, non-systematic reviews, reviews on nonrandomised trials and systematic reviews on exercise in the rehabilitation of acute injuries or musculoskeletal surgery were not included. Obesity was not considered as a disease in this review. Due to the large number of outcome variables only the clinically most important outcomes are included; these were selected on the basis of the author's clinical experience and contacts with different specialist doctors or scientists. Findings which lack a plausible explanation of the possible mechanisms underlying the effectiveness of the exercise therapy or which lack statistical power are not reported systematically in this review.

In systematic reviews the results can be given using different qualitative or quantitative (metaanalyses) techniques. For the most part, this summary review is based on the results of metaanalyses (table 1). Meta-analyses draw on a variety of techniques. The choice of technique depends on the nature of the data being analysed. For dichotomous (or binary) data the most commonly used summary statistics in exercise therapy studies are pooled odds ratios (ORs) or relative risks (RRs). For continuous data, whenever outcomes are measured in a standard way across studies, the weighted mean difference (WMD) is preferable. Where continuous outcomes are conceptually the same but measured in different ways, such as different pain scores in osteoarthritis, the results can be summarised using standardised (for standard deviations in the outcome measure) mean differences (SMDs). In cases where the data available do not enable statistical pooling, qualitative analysis is performed. In this article, categories of levels of evidence are not systematically reported, but the effects of exercise therapy are quantified as reported by the authors of specific meta-analyses. 
Before looking at the results of RCTs or the summary statistics of meta-analyses, critical analysis of the methodological quality of each individual RCT is important. Biased results from poorly designed and reported trials can mislead policy makers. ${ }^{2}$ As the assessment of quality scores of different RCTs have not been performed in a standard way in all systematic reviews, study quality is not systematically reported in this paper. The most common quality problems are discussed below (see Discussion).

\section{SUMMARY OF FINDINGS}

\section{Musculoskeletal diseases}

Based on a meta-analysis of 32 RCTs, land-based therapeutic exercise improved self-reported pain and self-reported physical function in patients with knee osteoarthritis (table 1). ${ }^{3}$ The effects were stronger in interventions with more than 12 directly supervised training sessions than in those with fewer such sessions. Higher quality studies reported somewhat smaller effect sizes compared to lower quality studies. Aerobic walking and lower limb strengthening exercises reduced pain and disability. ${ }^{3-5}$ The size of the effect of exercise in alleviating pain in hip osteoarthritis has been shown to be comparable to that in knee osteoarthritis. ${ }^{6}$ The benefits of aquatic exercise were rather similar to those of land-based exercise. ${ }^{7}$ The effect of exercise on the progression of osteoarthritis is unclear.

On the basis of more than 10 RCTs exercise therapy was effective in increasing aerobic capacity and muscle strength in patients with rheumatoid arthritis, ${ }^{89}$ although proper metaanalyses are lacking. Additionally, on the basis of three RCTs in patients under 18 years of age with juvenile idiopathic arthritis functional ability tended to be better after exercise therapy. ${ }^{10}$ No detrimental effects on disease activity and pain were observed. The effects of dynamic exercise therapy on radiological progression and cardiovascular disease need to be studied further. $^{89}$

Four RCTs compared an exercise program with no intervention in patients with ankylosing spondylolitis and reported some increases in spinal mobility and physical function. ${ }^{11}$

Three RCTs found exercise therapy to be not more effective than non-exercise for non-specific acute ( $<6$ weeks) low back pain. ${ }^{12}$ However, it should be noted that exercise therapy is not the same as advice to stay active, which is a recommended treatment strategy. In non-specific chronic ( $>12$ weeks) low back pain, the evidence suggests that exercise therapy is effective in improving pain outcomes (table 1). ${ }^{12}$ Additionally, a meta-analysis found that condition-specific functional outcomes improved, but that the effects were small (table 1). Individually designed strengthening or stabilising programs seem to be effective in healthcare settings. ${ }^{12}$ On the basis of 43 trials of 72 exercise treatment and 31 comparison groups, and using Bayesian multivariable random-effects meta-regression, Hayden et $a l^{13}$ found improved pain scores for individually designed programs, supervised home exercise and group and individually supervised programs compared with home exercises only.

In patients with fibromyalgia, aerobic exercise has been shown to increase physical function and global well-being as well as improve pain and possibly tender point pressure threshold (table 1). ${ }^{14}$ There is no conclusive evidence of the effects of strength training, although low quality evidence suggests that they are similar to those of aerobic training.

\section{Cardiovascular diseases}

According to the systematic review of Jolliffe et $a l^{15}$ exercise therapy in cases of documented coronary heart disease reduced all-cause mortality by $27 \%$ and total cardiac mortality by $31 \%$, but not the occurrence of non-fatal myocardial infarction (table 1). The patients included in the trials were predominantly middle-aged men who had suffered myocardial infarction. In a later review by Taylor et $a l^{16}$ in which the effect of endurance training alone or in combination with psychological or educational interventions were studied, the results for exercise-based rehabilitation on all-cause and cardiac mortality resembled those obtained earlier by Jolliffe et $a l^{15}$ A review of 16 RCTs showed that exercise training increased heart rate variability in patients with coronary artery disease. ${ }^{17}$

A review of 14 RCTs found physiological benefits of exercise therapy in heart failure patients. ${ }^{18}$ A positive training effect was documented in 12 out of 14 trials, with the results of 2 trials being inconclusive, and positive effects on some measures of quality of life were documented in 7 out of 9 trials. ${ }^{18}$ The patients included were predominantly men who were younger than most patients with heart failure and usually did not have other coexisting illnesses. In a later review by Rees et $a l^{19}$ these findings were confirmed with increases in maximal oxygen uptake, exercise duration, maximum work capacity and distance walked in 6 min (table 1). In the meta-analysis of Smart and Marwick, ${ }^{20}$ during the training and follow-up periods there was a statistically non-significant trend to reduced mortality in the exercise compared to control groups (table 1).

Physical training studies on intermittent claudication consistently reported that training increases walking time and walking distance as well as pain-free walking time and walking distance (table 1), but not peak exercise calf blood flow. ${ }^{21}$ Supervised training showed stronger improvement in maximal treadmill walking when compared with the results of nonsupervised exercise therapy regimens. ${ }^{22}$

Gait-oriented exercise training was effective in improving walking speed and distance in patients with stroke (table 1). ${ }^{23}$

RCTs on hypertensive subjects have shown a clear lowering effect on blood pressure of aerobic training (table 1). ${ }^{24}$ In the exercise training groups vascular resistance, plasma norepinephrine and plasma renin activity decreased. At the moment there is no conclusive evidence available on the effects of resistance training on blood pressure in hypertensive subjects. ${ }^{25}$

In patients with cardiovascular disease a review of six studies concluded that aerobic exercise was effective in increasing HDL cholesterol and a review of nine studies that aerobic exercise induced a reduction in triglycerides (table 1). ${ }^{26}$

\section{Type 2 diabetes mellitus}

Postintervention glycated haemoglobin values were significantly lower in the exercise groups compared with control groups (table 1), while body mass was not. ${ }^{27}$ The authors concluded that the group difference in glycated haemoglobin was large enough significantly to reduce the risk of diabetic complications. According to another systematic review, based on nine RCTs, regular exercise has a statistically and clinically significant effect on maximal oxygen uptake in type 2 diabetic individuals. ${ }^{28}$ Interestingly, recently published randomised trials show that resistance training improves glycaemic control in patients with type 2 diabetes. ${ }^{29}{ }^{30}$

In a review of four studies aerobic exercise was effective in reducing $\mathrm{LDL}$ cholesterol in patients with type 2 diabetes (table 1). ${ }^{31}$ 
Table 1 Results of selected meta-analyses of randomised controlled trials on the benefits of exercise therapy in the treatment of patients with specific diseases

\begin{tabular}{|c|c|c|c|c|}
\hline Study, year & Disease & Outcome measure & No. studies (no. participants) & $\begin{array}{l}\text { Effect size of exercise compared to controls, } \\
\text { pooled statistics }(95 \% \mathrm{Cl})^{*}\end{array}$ \\
\hline Fransen et al, $2008^{3}$ & Osteoarthritis & Self-reported pain & $32(3616)$ & $\begin{array}{l}\text { Standardised mean difference }-0.40(-0.50 \text { to } \\
-0.30)\end{array}$ \\
\hline Fransen et al, $2008^{3}$ & Osteoarthritis & $\begin{array}{l}\text { Self-reported physical function } \\
\text { limitations }\end{array}$ & $31(3719)$ & $\begin{array}{l}\text { Standardised mean difference }-0.37(-0.49 \text { to } \\
-0.25)\end{array}$ \\
\hline $\begin{array}{l}\text { Hernandez-Molina et al, } \\
2008^{6}\end{array}$ & Hip osteoarthritis & Self-reported pain & $8(493)$ & $\begin{array}{l}\text { Standardised mean difference }-0.46(-0.64 \text { to } \\
-0.28)\end{array}$ \\
\hline Hayden et al, $2005^{12}$ & $\begin{array}{l}\text { Non-specific chronic (> } \\
12 \text { weeks) low back pain }\end{array}$ & $\begin{array}{l}\text { Pain, visual analogue scale } \\
\text { (scaled to } 0 \text { to } 100 \text { points) }\end{array}$ & $8(370)$ & $\begin{array}{l}\text { Weighted mean difference }-10.20 \text { points }(-19.09 \text { to } \\
-1.31)\end{array}$ \\
\hline Hayden et al, $2005^{12}$ & $\begin{array}{l}\text { Non-specific chronic (> } \\
12 \text { weeks) low back pain }\end{array}$ & $\begin{array}{l}\text { Condition-specific functioning } \\
\text { limitations (scaled to } 0 \text { to } 100 \\
\text { points) }\end{array}$ & $7(337)$ & $\begin{array}{l}\text { Weighted mean difference }-2.97 \text { points }(-6.48 \text { to } \\
0.53)\end{array}$ \\
\hline Busch et al, $2007^{14}$ & Fibromyalgia & Pain & $4(223)$ & $\begin{array}{l}\text { Standardised mean difference }-0.81(-1.47 \text { to } \\
-0.15)\end{array}$ \\
\hline Busch et al, $2007^{14}$ & Fibromyalgia & Tender points & $6(349)$ & Standardised mean difference $-0.76(-1.53$ to 0.01$)$ \\
\hline Busch et al, $2007^{14}$ & Fibromyalgia & Global well-being & $4(269)$ & Standardised mean difference $0.49(0.23$ to 0.75$)$ \\
\hline Busch et al, $2007^{14}$ & Fibromyalgia & Physical function & $4(253)$ & Standardised mean difference 0.66 (0.41 to 0.92$)$ \\
\hline Jolliffe et al, $2001^{15}$ & Coronary heart disease & All cause mortality & $12(2582)$ & Odds ratio 0.73 (0.54 to 0.98$)$ \\
\hline Jolliffe et al, $2001^{15}$ & Coronary heart disease & Cardiac mortality & $8(2312)$ & Odds ratio 0.69 (0.51 to 0.94$)$ \\
\hline Jolliffe et al, $2001^{15}$ & Coronary heart disease & Non-fatal myocardial infarction & $9(2104)$ & Odds ratio 0.96 (0.69 to 1.35$)$ \\
\hline Nolan et al, $2008^{17}$ & Coronary heart disease & Heart rate variability & $16(631)$ & Standardised mean difference 0.36 (0.18 to 0.55$)$ \\
\hline Rees et al, $2004^{19}$ & Heart failure & Maximal oxygen uptake & $24(848)$ & $\begin{array}{l}\text { Weighted mean difference } 2.16 \mathrm{ml} / \mathrm{kg} / \mathrm{min}(1.49 \text { to } \\
\text { 2.82) }\end{array}$ \\
\hline Rees et al, $2004^{19}$ & Heart failure & Distance on 6-min walk & $8(282)$ & Weighted mean difference $41 \mathrm{~m}$ (17 to 65 ) \\
\hline $\begin{array}{l}\text { Smart and Marwick, } \\
2004^{20}\end{array}$ & Heart failure & Mortality & $30(1197)$ & Odds ratio $0.71(0.37,1.02)$ \\
\hline Watson et al, $2008^{21}$ & Intermittent claudication & Maximal walking time & $7(255)$ & Weighted mean difference $5.12 \mathrm{~min}$ (4.51 to 7.52 ) \\
\hline van de Port et al, $2007^{23}$ & Stroke & Maximum walking speed & $12(501)$ & Standardised effect size $0.45(0.27$ to 0.63$)$ \\
\hline van de Port et al, $2007^{23}$ & Stroke & Walking distance & $9(451)$ & Standardised effect size 0.62 (0.30 to 0.95$)$ \\
\hline $\begin{array}{l}\text { Cornelissen and Fagard, } \\
2005^{24}\end{array}$ & Hypertension & Systolic blood pressure & $30(492)$ & Mean net change $-6.9 \mathrm{~mm} \mathrm{Hg}(-9.1$ to -4.6$)$ \\
\hline $\begin{array}{l}\text { Cornelissen and Fagard, } \\
2005^{24}\end{array}$ & Hypertension & Diastolic blood pressure & $30(492)$ & Mean net change $-4.9 \mathrm{~mm} \mathrm{Hg}(-6.5$ to -3.3$)$ \\
\hline Kelley et al, $2006^{26}$ & Cardiovascular disease & HDL cholesterol & $6(637)$ & Weighted mean difference $3.7 \mathrm{mg} / \mathrm{dl}$ (1.2 to 6.1 ) \\
\hline Kelley et al, $2006^{26}$ & Cardiovascular disease & Triglycerides & $9(1172)$ & $\begin{array}{l}\text { Weighted mean difference }-19.3 \mathrm{mg} / \mathrm{dl}(-30.1 \text { to } \\
-8.5)\end{array}$ \\
\hline Thomas et al, $2006^{27}$ & Type 2 diabetes & $\begin{array}{l}\text { Glycated haemoglobin } \\
\text { percentage }\left(\mathrm{HbA}_{1 \mathrm{c}}\right)\end{array}$ & $13(361)$ & $\begin{array}{l}\text { Weighted mean difference }-0.62 \%(-0.91 \% \text { to } \\
-0.33 \%)\end{array}$ \\
\hline Boyle et al, $2003^{28}$ & Type 2 diabetes & Maximal oxygen uptake & $9(266)$ & Standardised mean difference 0.53 (0.18 to 0.88$)$ \\
\hline $\begin{array}{l}\text { Kelley and Kelley, } \\
2007^{31}\end{array}$ & Type 2 diabetes & LDL cholesterol & $4(156)$ & $\begin{array}{l}\text { Weighted mean difference }-6.4 \mathrm{mg} / \mathrm{dl}(-11.8 \text { to } \\
-1.1)\end{array}$ \\
\hline Ram et al, $2005^{32}$ & Asthma & Resting lung function (FEV1) & $5(129)$ & Weighted mean difference 0.01 litres $(-0.14$ to 0.16$)$ \\
\hline Ram et al, $2005^{32}$ & Asthma & Maximal ventilation $\left(\mathrm{VE}_{\max }\right)$ & $4(111)$ & $\begin{array}{l}\text { Weighted mean difference } 6.00 \text { litres/min (1.57 to } \\
10.43)\end{array}$ \\
\hline Ram et al, $2005^{32}$ & Asthma & Maximal oxygen uptake & $7(175)$ & Weighted mean difference $5.4 \mathrm{ml} / \mathrm{kg} / \mathrm{min}$ (4.2 to 6.6) \\
\hline Salman et al, $2003^{33}$ & COPD & Walking distance & $20(979)$ & Standardised effect size 0.71 (0.43 to 0.99$)$ \\
\hline Salman et al, $2003^{33}$ & COPD & $\begin{array}{l}\text { Shortness of breath by Chronic } \\
\text { Respiratory Disease } \\
\text { Questionnaire }\end{array}$ & $12(723)$ & Standardised effect size $-0.62(-0.91$ to -0.26$)$ \\
\hline Goodwin et al, $2008^{36}$ & Parkinson disease & Physical functioning limitations & $7(360)$ & $\begin{array}{l}\text { Standardised mean difference }-0.47(-0.82 \text { to } \\
-0.12)\end{array}$ \\
\hline Goodwin et al, $2008^{36}$ & Parkinson disease & $\begin{array}{l}\text { Health-related quality of life } \\
\text { limitations }\end{array}$ & $4(292)$ & $\begin{array}{l}\text { Standardised mean difference }-0.27(-0.51 \text { to } \\
-0.04)\end{array}$ \\
\hline Heyn et al, $2004^{38}$ & Cognitive impairment & Cardiovascular fitness & $18(1059)$ & Standardised effect size 0.62 ( 0.45 to 0.78$)$ \\
\hline Heyn et al $2004^{38}$ & Cognitive impairment & Cognitive outcomes & $12(820)$ & Standardised effect size 0.57 (0.38 to 0.75$)$ \\
\hline Mead et al, $2008^{39}$ & Depression & Depression symptoms & $23(907)$ & $\begin{array}{l}\text { Standardised mean difference }-0.82(-1.12 \text { to } \\
-0.51)\end{array}$ \\
\hline Edmonds et al, $2004^{40}$ & Chronic fatigue syndrome & Chalder fatigue scale & $5(286)$ & $\begin{array}{l}\text { Standardised mean difference }-0.77(-1.26 \text { to } \\
-0.28)\end{array}$ \\
\hline Edmonds et al, $2004^{40}$ & Chronic fatigue syndrome & $\begin{array}{l}\text { Quality of life limitations, SF-36 } \\
\text { physical functioning subscale }\end{array}$ & $3(162)$ & $\begin{array}{l}\text { Standardised mean difference }-0.64(-0.96 \text { to } \\
-0.33)\end{array}$ \\
\hline Shamliyan et al, $2008^{41}$ & Urinary incontinence & Contingence rate & $4(647)$ & Pooled risk difference $0.13(0.07$ to 0.20$)$ \\
\hline Markes et al, $2006^{42}$ & Breast cancer & Cardiorespiratory fitness & $5(207)$ & Standardised mean difference $0.66(0.20$ to 1.12$)$ \\
\hline $\begin{array}{l}\text { Cramp and Daniel, } \\
2008^{43}\end{array}$ & Cancer & Fatigue & $30(1662)$ & $\begin{array}{l}\text { Standardised mean difference }-0.23(-0.33 \text { to } \\
-0.13)\end{array}$ \\
\hline
\end{tabular}

*All estimates reported in this table favour exercise groups; effect sizes as reported by the authors of original meta-analyses.

COPD, chronic obstructive pulmonary disease; HDL, high-density lipoprotein; FEV1, forced expiratory volume in 1 s; LDL, low-density lipoprotein, SF-36, Short Form 36 questionnaire. 


\section{Pulmonary diseases}

According to the systematic review of Ram et al ${ }^{32}$ cardiorespiratory fitness of patients with asthma can be increased by physical training (table 1), although no evidence was found of an effect on measures of resting pulmonary function.

Salman et $a^{33}$ found that rehabilitation groups (20 trials) of patients with chronic obstructive pulmonary disease (COPD) did significantly better than control groups in a walking test (table 1). In 12 trials where the Chronic Respiratory Disease Questionnaire had been administered the rehabilitation groups had less shortness of breath than the controls. In trials where only respiratory muscle training was used no significant difference was observed between the rehabilitation and control groups, whereas in trials including at least lower extremity training rehabilitation groups did significantly better than the controls in the walking test and had less shortness of breath. However, Geddes et $a^{134}$ reported in their systematic review that inspiratory muscle training benefited patients with COPD, including improved 6-min walk test performance. The findings of the meta-analysis by Lacasse et $a l^{35}$ are in accordance with those of Salman et al, ${ }^{33}$ showing that exercise-based rehabilitation decreases dyspnoea symptoms and increases exercise capacity.

\section{Neurological diseases}

According to a meta-analysis, exercise therapy/exercise-based physiotherapy improved physical functioning (seven trials) and health-related quality of life (four trials) in patients with Parkinson disease. ${ }^{36}$ In addition, the exercise groups had improved balance in four out of five trials and higher walking speed in three out of four trials. ${ }^{36}$

A best evidence synthesis of six RCTs was strongly in favour of exercise therapy compared to no exercise therapy of muscle power function, exercise tolerance functions and mobilityrelated activities in patients with multiple sclerosis. ${ }^{37}$ Moderate evidence was found for improved mood. No effect was observed for exercise therapy on fatigue and perception of handicap.

There are too few studies on patients diagnosed as having dementia to allow conclusions to be drawn. However, physical exercise was beneficial for older persons ( $\geqslant 65$ years; 30 trials with a total of 2020 participants) with cognitive impairment or dementia as the interventions improved cardiovascular fitness, strength, flexibility, and functional, cognitive and behavioural outcomes (table 1). ${ }^{38}$

\section{Other diseases}

In a study of 23 RCTs, exercise intervention reduced symptoms of depression (table 1), ${ }^{39}$ although many of the RCTs were of low methodological quality and the high quality studies showed results with lower effect sizes.

Chronic fatigue syndrome is an illness characterised by persistent, medically unexplained fatigue that has lasted for at least 6 months. A review of five RCTs found that subjects receiving exercise therapy were less fatigued than controls. ${ }^{40}$ Physical functioning also significantly improved with exercise therapy.

Shamliyan et $a l^{41}$ found in their meta-analysis that pelvic floor muscle training and bladder training consistently increased continence rates (table 1) in women with stress urinary incontinence.

During adjuvant treatment for breast cancer, RCTs have shown increased cardiorespiratory fitness in the exercise groups compared with controls. ${ }^{42}$ Exercise was beneficial for cancerrelated fatigue (table 1) during and after cancer therapy. ${ }^{43}$

\section{DISCUSSION}

Clinically most important effects of exercise therapy and the size of effects

Exercise therapy can have a positive effect on health via many disease-specific mechanisms (fig 1). The most consistent finding of the various studies conducted to date included in this summary review is that aerobic/functional capacity and/or muscle strength can be improved by exercise training among patients with different chronic diseases. ${ }^{3} 1215192123283233363842$ This is important as the proportion of older people is increasing and exercise therapy may be an important means to reduce disability and increase the numbers of those able to live independently in the community. The finding that aerobic exercise training consistently increases physical performance capacity and maximal oxygen uptake in patients with chronic diseases is important as observational studies have shown that low aerobic fitness is an important risk factor for mortality in this population segment, ${ }^{44}$ as it has been shown to be among apparently healthy people. ${ }^{45}$ Higher intensity training is more effective than lower-intensity training in increasing maximal oxygen among healthy subjects ${ }^{46}$ and among patients with cardiac issues. ${ }^{47-49}$ However, little research evidence is available as yet on what training intensity would be most beneficial for the long-term prognosis of different diseases.

Other cardiometabolic risk factors have also been found to benefit from exercise. ${ }^{24262731}$ Of particular importance is the finding, on the basis of randomised trials, that exercise reduces visceral fat among adults ${ }^{50}$ and percentage body fat among children, ${ }^{51}$ including in the absence of changes in total body weight, as skeletal muscle mass often increases as a consequence of exercise training.

The effect sizes of exercise therapy on different outcomes vary from no effect to strong effect (table 1). When compared to pharmacological therapy, exercise usually has positive effects via many different mechanisms (fig 1), although pharmacological treatment targeted at a specific parameter, such as antihypertensive drugs, ${ }^{52}$ may have an effect size as high, if not higher. The possible overall strong health benefit of exercise therapy in the prevention and treatment of a disease seems to be a sum effect mediated via different mechanisms.

\section{Methodological considerations and main limitations}

Based on the most recent criteria for designing RCTs, the oldest RCTs in the literature are usually of low quality while recently published RCTs are generally of higher quality. Heterogeneity in the results often means that the studies are of low or varying quality, as is the case, for example, in studies on depression. First, it should be borne in mind that clinical trials using nonpharmacological treatments, such as exercise therapy, are less often rigorously blinded or placebo-controlled than pharmacological clinical trials. ${ }^{53}$ Some of the results of the trials may at least in part be explained by the placebo effect. Another common problem in exercise therapy studies is the insufficient documentation and analysis of possible co-interventions, such as changes in medication or diet. Compared with many pharmacological trials the low number of participants and lack of documentation of all the complications and side effects arising from many of the interventions is also a limitation. The fact that most trials are of short duration means that some benefits, such as increases in physical fitness, are attained 
Figure 1 Main evidence-based pathways on how physical activity or exercise therapy delays progression of diseases and occurrence of disability and deaths.

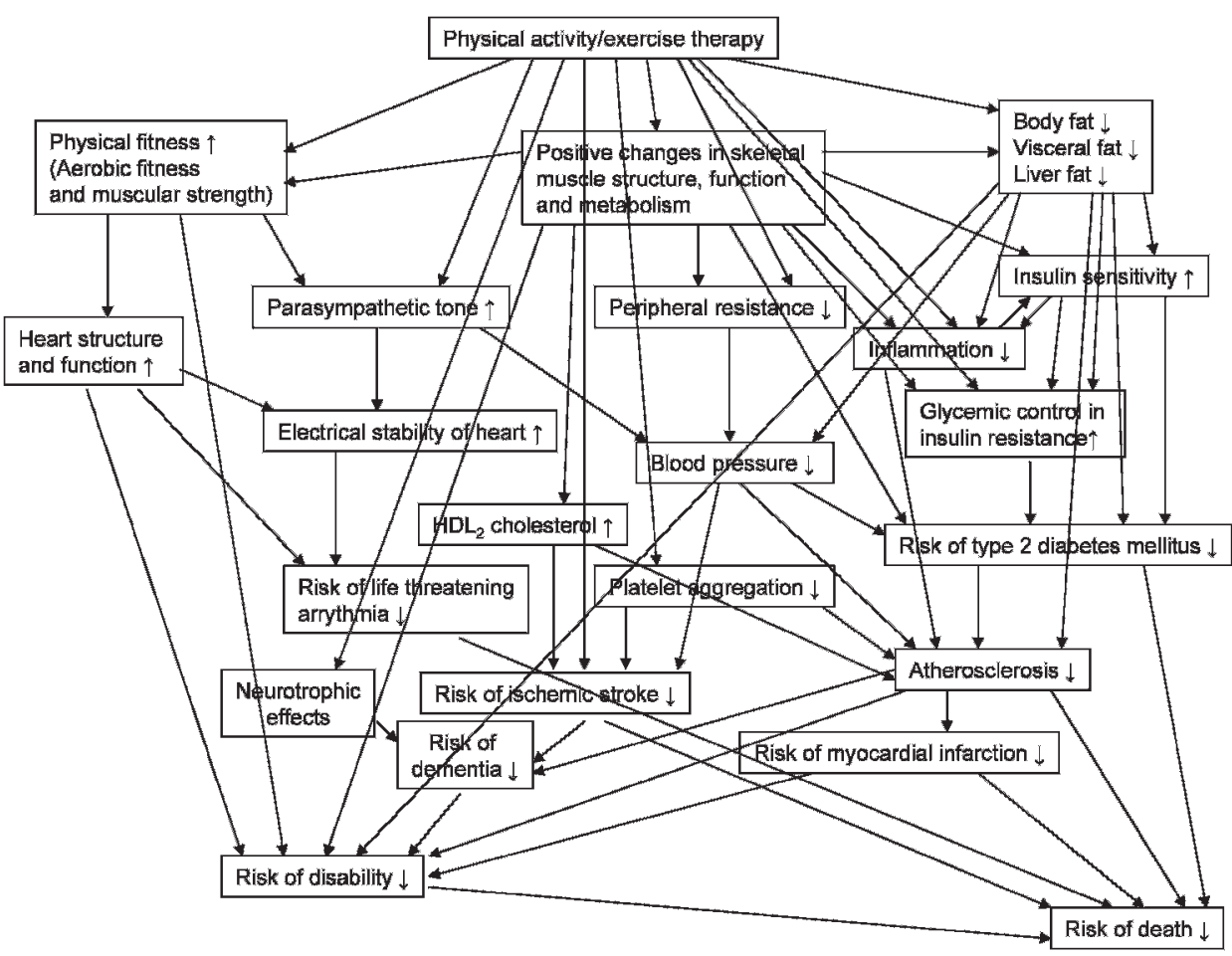

within a few months. However, the duration of most RCTs usually is too short to provide conclusive evidence on the effects of exercise therapy on the true progression of disease.

Generalisability may be a further problem as some RCTs include patients who are not representative of the general population of patients with respect to age, gender and coexisting diseases. This is typically seen in RCTs on coronary heart disease ${ }^{15}$ and heart failure. ${ }^{18}$ There is a need for high quality RCTs with long-term follow-ups including documentation of such outcomes as survival rate, hospitalisation rate and healthcare costs as well as side effects and complications.

\section{What is already known on this topic}

- Published consensus statements summarise that on the basis of observational follow-up studies it is known that baseline high physical activity is associated with many health benefits later in life.

- Similar up-to-date summaries on the effects of exercise therapy in the treatment of chronic diseases are lacking.

\section{What this study adds}

- The findings of the meta-analyses of randomised controlled trials summarised in this paper include that aerobic/functional capacity and muscle strength as well as prognostic risk factor profile can be improved by exercise training among patients with different diseases.

- Exercise therapy can have positive effects on health via many disease-specific mechanisms.

\section{Practical challenges}

Doctors play a central role in the evaluation of risks and in patient motivation when prescribing exercise to patients with chronic diseases. Sometimes collaboration with an exercise physiologist, physiotherapist etc. will be beneficial when determining correct exercise intensities and in tailoring and supervising training programs; however, doctors are still expected to know what the guidelines ${ }^{54}$ are when they prescribe exercise therapy for their patients. In carefully designed RCTs, the screening of the risks for patients and the exercise program take safety issues into account on the individual level.

To date only a few scattered studies have analysed the possible beneficial dose-response of specific exercise therapies. Since in exercise therapy long-term adherence is a general problem, supervised exercise programs usually give better results than non-supervised programs although the cost-effectiveness of non-supervised programs may be higher.

\section{Conclusions}

The most consistent finding of the review studies summarised here is that aerobic/functional capacity and muscle strength can be improved by exercise training among patients with different diseases without having detrimental effects on disease progression. This is important, as with population aging exercise therapy may be an important means of reducing disability and increasing the number of older people living independently. Severe complications during these carefully tailored programs were rare. In some diseases, such as osteoarthritis, pain symptoms may also be reduced. As this review shows, there is accumulating evidence that in patients with chronic disease exercise therapy is effective in improving the prognostic risk factor profile.

Competing interests: None.

Provenance and peer review: Not commissioned; externally peer reviewed. 


\section{REFERENCES}

1. Kujala UM. Evidence for exercise therapy in the treatment of chronic disease based on at least three randomized controlled trials - summary of published systematic reviews. Scand J Med Sci Sports 2004;14:339-45.

2. Altman DG, Schulz KF, Moher D, et al. The revised CONSORT statement for reporting randomized trials: explanation and elaboration. Ann Intern Med 2001;134:663-94.

3. Fransen M, McConnell S, Bell M. Exercise for osteoarthritis of the hip or knee. Cochrane Database Syst Rev 2008;4:CD004376.

4. Roddy E, Zhang W, Doherty M. Aerobic walking or strengthening exercise fo osteoarthritis of the knee? A systematic review. Ann Rheum Dis 2005:64:544-8.

5. Lange AK, VanWanseele B, Fiatore Singh MA. Strength training for treatment of osteoarthritis of the knee: a systematic review. Arthritis Rheum (Arthritis Care Res) 2008:59:1488-94.

6. Hernandez-Molina G, Reichenbach S, Zhang B, et al. Effect of therapeutic exercise for hip osteoarthritis pain: results of a meta-analysis. Arthritis Rheum (Arthritis Care Res) 2008;59:1221-8

7. Bartels EM, Lund $\mathrm{H}$, Hagen $\mathrm{KB}$, et al. Aquatic exercise for the treatment of knee and hip osteoarthritis. Cochrane Database Syst Rev 2007:4:CD005523.

8. Kettunen JA, Kujala UM. Exercise therapy for people with rheumatoid arthritis and osteoarthritis. Scand J Med Sci Sports 2004;14:138-42.

9. Metsios GS, Stavropoulos-Kalinoglou A, Veldhuijzen van Zanten JJCS, et al. Rheumatoid arthritis, cardiovascular disease and physical exercise: a systematic review. Rheumatology 2008;47:239-48.

10. Takken T, Van Brussel $\mathrm{M}$, Engelberg $\mathrm{RH}$, et al. Exercise therapy in juvenile idiopathic arthritis. Cochrane Database Syst Rev 2008;4:CD005954.

11. Dagfinrud H, Kvien TK, Hagen KB. Physiotherapy interventions for ankylosing spondylolitis. Cochrane Database Syst Rev 2008;1:CD002822.

12. Hayden JA, van Tulder MW, Malmivaara AV, et al. Exercise therapy for non-specific low back pain. Cochrane Database Syst Rev 2005;3:CD000335.

13. Hayden JA, van Tulder MW, Tomlinson G. Systematic review: strategies for using exercise therapy to improve outcomes in chronic low back pain. Ann Intern Med 2005:142:776-85.

14. Busch AJ, Barber KA, Overend TJ, et al. Exercise for treating fibromyalgia syndrome. Cochrane Database Syst Rev 2007;4:CD003786.

15. Jolliffe JA, Rees $\mathrm{K}$, Taylor RS, et al. Exercise-based rehabilitation for coronary heart disease. Cochrane Database Syst Rev 2001;1:CD001800.

16. Taylor RS, Brown A, Ebrahim S, et al. Exercise-based rehabilitation for patients with coronary heart disease: systematic review and meta-analysis of randomized controlled trials. Am J Med 2004;116:682-92.

17. Nolan RP, Jong P, Barry-Bianchi SM, et al. Effects of drug, biobehavioral and exercise therapies on heart rate variability in coronary artery disease: a systematic review. Eur J Cardiovasc Prev Rehabil 2008;15:386-96.

18. Lloyd-Williams F, Mair FS, Leitner M. Exercise training and heart failure: a systematic review of current evidence. Br J Gen Pract 2002;52:47-55.

19. Rees K, Taylor RS, Singh S, et al. Exercise-based rehabilitation for heart failure. Cochrane Database Syst Rev 2004;3:CD003331.

20. Smart N, Marwick TH. Exercise training for patients with heart failure: a systematic review of factors that improve mortality and morbidity. Am J Med 2004;116:693-706.

21. Watson L, Ellis B, Leng GC. Exercise for intermittent claudication. Cochrane Database Syst Rev 2008;4:CD000990

22. Bendermacher BLW, Willigendael EM, Teijink JAW, et al. Supervised exercise therapy versus non-supervised exercise therapy for intermittent claudication. Cochrane Database Syst Rev 2006;2:CD005263.

23. Van de Port IGL, Wood-Dauphinee S, Lindeman E, et al. Effects of exercise training programs on walking competency after stroke. A systematic review. Am J Phys Med Rehabil 2007;86:935-51.

24. Cornelissen VA, Fagard RH. Effect of endurance training on blood pressure, blood pressure-regulating mechanisms, and cardiovascular risk factors. J Hypertens 2005;23:251-9.

25. Cornelissen VA, Fagard $\mathrm{BH}$. Effect of resistance training on resting blood pressure: a meta-analysis of randomized controlled trials. J Hypertens 2005;23:251-9.

26. Kelley GA, Kelley KS, Franklin B. Aerobic exercise and lipids and lipoproteins in patients with cardiovascular disease: A meta-analysis of randomized controlled trials. J Cardiopulm Rehabil 2006;26:131-9.

27. Thomas D, Elliot EJ, Naughton GA. Exercise for type 2 diabetes mellitus. Cochrane Database Syst Rev 2006;3:CD002968.

28. Boule NG, Kenny GP, Haddad E, et al. Meta-analysis of the effect of structured exercise training on cardiorespiratory fitness in type 2 diabetes mellitus. Diabetologia 2003;46:1071-81.
29. Snowling NJ, Hopkins WG. Effect of different modes of exercise training on glucose control and risk factors for complications in type 2 diabetic patients. A meta-analysis. Diabetes Care 2006;29:2518-27.

30. Sigal RJ, Kenny GP, Boule NG, et al. Effects of aerobic training, resistance training, or both on glycemic control on type 2 diabetes: a randomized trial. Ann Intern Med 2007; 147:357-69.

31. Kelley GA, Kelley KS. Effects of aerobic exercise on lipids and lipoproteins in adults with type 2 diabetes: A meta-analysis of randomized-controlled trials. Public Health 2007:121:643-55.

32. Ram FSF, Robinson SM, Black PN, et al. Physical training for asthma. Cochrane Database Syst Rev 2005:4:CD001116.

33. Salman GF, Mosier MC, Beasley BW, et al. Rehabilitation for patients with chronic obstructive pulmonary disease: meta-analysis of randomized controlled trials. J Gen Intern Med 2003:18:213-21.

34. Geddes EL, O'Brien K, Reid WD, et al. Inspiratory muscle training in adults with chronic obstructive pulmonary disease: An update of a systematic review. Respirat Med 2008;102:1715-29.

35. Lacasse Y, Goldstein R, Lasserson TJ, et al. Pulmonary rehabilitation for chronic obstructive pulmonary disease. Cochrane Database Syst Rev 2006:4:CD003793.

36. Goodwin VA, Richards SH, Taylor RS, et al. The effectiveness of exercise interventions for people with Parkinson's disease: a systematic review and metaanalysis. Mov Disord 2008:23:631-40.

37. Rietberg MB, Brooks D, Uitdehaag BMJ, et al. Exercise therapy for multiple sclerosis. Cochrane Database Syst Rev 2004;3:CD003980.

38. Heyn P, Abreu BC, Ottenbacher KJ. The effects of exercise training on elderly persons with cognitive impairment and dementia: a meta-analysis. Arch Phys Med Rehabil 2004;85:1694-704.

39. Mead GE, Morley W, Campbell P, et al. Exercise for depression. Cochrane Database Syst Rev 2008;4:CD004366.

40. Edmonds $\mathbf{M}$, McGuire H, Price J. Exercise therapy for chronic fatigue syndrome. Cochrane Database Syst Rev 2004;3:CD003200.

41. Shamliyan TA, Kane RL, Wyman J, et al. Systematic review: randomized, controlled trials of nonsurgical treatments for urinary incontinence in women. Ann Intern Med 2008;148:456-7.

42. Markes $\mathbf{M}$, Brockow T, Resch KL. Exercise for women receiving adjuvant therapy for breast cancer. Cochrane Database Syst Rev 2006;4:CD005001.

43. Cramp F, Daniel J. Exercise for the management of cancer-related fatigue in adults Cochrane Database Syst Rev 2008;2:CD005001.

44. Myers J, Prakash M, Froelicher V, et al. Exercise capacity and mortality among men referred for exercise testing. N Engl J Med 2002;346:793-801.

45. Physical Activity Guidelines Advisory Committee. Physical Activity Guidelines Advisory Committee report, 2008. Washington, DC, USA: US Department of Health and Human Services, 2008.

46. Gormley SE, Swain DP, High R, et al. Effect of intensity of aerobic training on $\mathrm{VO}_{2 \mathrm{max}}$. Med Sci Sports Exerc 2008;40:1336-43.

47. Rognmo 0, Hetland E, Helgerud J, et al. High intensity aerobic interval exercise is superior to moderate intensity exercise for increasing aerobic capacity in patients with coronary artery disease. Eur J Cardiovasc Prev Rehabil 2004;11:216-22.

48. Warburton DER, McKenzie DC, Haykowsky MJ, et al. Effectiveness of high-intensity interval training for the rehabilitation of patients with coronary artery disease. Am J Cardiol 2005;95:1080-4.

49. Wisloff U, Stoylen A, Loennechen JP, et al. Superior cardiovascular effect of aerobic interval training versus moderate continuous training in heart failure patients Circulation 2007:115:3086-94.

50. Ohkawara K, Tanaka S, Miyachi M, et al. A dose-response relation between aerobic exercise and visceral fat reduction: systematic review of clinical trials. Int $\mathrm{J}$ Obesity 2007:31:1786-97.

51. Atlantis E, Barnes EH, Fiatore Singh MA. Efficacy of exercise for treating overweight in children and adolescents: a systematic review. Int J Obesity 2006;30:1027-40.

52. Law MR, Wald NJ, Morris JK, et al. Value of low dose combination treatment with blood pressure lowering drugs: analysis of 354 randomized trials. BMJ 2003; 326:1427.

53. Boutron I, Tubach F, Giraudeau B, et al. Methodological differences in clinical trials evaluating nonpharmacological and pharmacological treatments of hip and knee osteoarthritis. JAMA 2003;290:1062-70

54. American College of Sports Medicine. ACSM's guidelines for exercise testing and prescription, 7th edn. Philadelphia, Pennsylvania, USA: Lippincott Williams and Wilkins, 2005:366. 